\title{
Local exhaust ventilation solutions for an industrial hall - Part 1 CFD analysis of the local exhaust systems
}

\author{
George-Mădălin Chitaru ${ }^{1, *}$, Mihnea Sandu ${ }^{1}$, Cristiana Verona Croitoru $^{1}$ and Florin Bode ${ }^{2}$ \\ ${ }^{1}$ UTCB Faculty of Building Services, 021414 Pache Protopopescu Blvd., Bucharest, Romania \\ ${ }^{2}$ Technical University of Cluj-Napoca, 400114 Cluj-Napoca, Romania
}

\begin{abstract}
Industrial hygiene is an important aspect of any workplace environment, especially for the industrial domain. A previous study has shown that high ammonia levels were present in a wastewater treatment facility in Romania. The initial ventilation strategy was not efficient in maintaining pollutant concentrations within standard safety limits. An optimization of the initial ventilation system was realized, but CFD results and on-site measurements have shown that high local concentrations were still present. Two local exhaust methods have been proposed and analysed in order to improve the quality of the air inside the hall. A CFD approach has been used for the preliminary design process. The results indicate that both local exhaust solutions offer great improvements over the general dilution-based system, but only one can be applied.
\end{abstract}

\section{Introduction}

Even though modern industry has mainly developed within the past century, the concept of "industrial hygiene" has been developed over the course of almost 20 centuries. Since antiquity there has been an awareness regarding the safety and health of the workers, especially of those that were operating in mines or that were exposed to different toxins like lead, sulfur, mercury or nitric acid. The first book, tied to this subject, has been written in the 16th century by Georgius Agricola and it was intended to suggest measures of protecting the workers from mining accidents and related diseases. Nowadays, industrial hygiene is a complex science which aims to provide adequate workplace conditions by anticipating, recognizing, evaluating and controlling indoor factors to avoid injury, illness and any potential health hazards. (OSHA, 1998)

One of the most important aspects of a healthy workplace is to provide an adequate indoor air quality (IAQ) and thermal comfort for the workers [(OSHA, 2011), (WHO, 2006)]. As for every type of building, a good indoor environmental quality (IEQ) is assured through a well-designed HVAC system. However, besides controlling the ambient conditions like indoor temperature, air humidity, air velocity etc., industrial ventilation systems also have an important role in controlling the level of contaminants like indoor pollutants, particulate matter, toxic wastes, odor or explosive gases. In order to aid the HVAC engineers, there are now guides and regulations that specify recommended or mandatory occupational safety and health requirements for different situations (ACGIH, 2016). Nonetheless, there are still many uncertainties that can arise due to a plethora of potential complications and different scenarios. Therefore, properly designing an industrial ventilation system can become a difficult task, especially nowadays when energy efficiency has become a critical factor in the conception of any HVAC installation. Hence a balance needs to be found so that all safety factors are respected with the least consumption of energy.

When talking about air pollution control solutions, computational fluid dynamics (CFD) has become an important tool that can aid HVAC engineers in designing more efficient ventilation systems. A proper CFD model can offer great advantages like: deciding the best positioning of the inlets and the outlets, finding a suitable airflow that offers good IAQ levels with lower energy consumption, verifying for draft or stagnation zones or running a preliminary check for the containment efficiency of local exhaust systems.

The current paper continues the work presented in (Croitoru, et al., 2017) by detailing the preliminary design process for a local exhaust ventilation solution for the wastewater treatment facility located in Glina county, Romania. The main objective of the project is to find a more suitable way to ventilate the industrial hall in order to reduce the indoor pollutant concentrations to an acceptable level and, at the same time, to ensure an adequate thermal comfort level. The main pollutant that represents a potential risk for the worker's wellbeing is the ammonia $\left(\mathrm{NH}_{3}\right)$ produced by the sludge resulted in the process. The preliminary measurements from (Croitoru, et al., 2017) have shown that elevated indoor concentrations are present during working hours. The levels of ammonia are therefore high enough to provoke headaches, nausea or nose, eye and throat irritations. Moreover, the sharp odor of ammonia represents a real discomfort for the workers (Wisconsin Department of Health Services, 2000). Therefore, the threshold for the acceptable level should take into consideration the limits specified in the literature (European Comission, 2000), but also the feedback input from the workers within the

\footnotetext{
* Corresponding author: chitarumadalin@gmail.com
} 
facility, because ammonia has a very strong and persisting smell even at low concentrations.

\section{Details of the studied hall}

The industrial hall has a rectangular shape with dimensions of $37.6 \mathrm{~m} \times 18.1 \mathrm{~m} \times 13.5 \mathrm{~m}$. The building has 6 big doors $(4 \mathrm{~m} \times 5 \mathrm{~m})$ for the extraction of the sludge containers and 2 small doors $(3 \mathrm{~m} \times 3 \mathrm{~m})$ for personnel access. Inside the building there are 6 sludge containers, 3 centrifuge decanters, 3 lime silos, 3 polymer preparation units and the conveyor system with all ducts, rotary screws and auxiliary equipment.

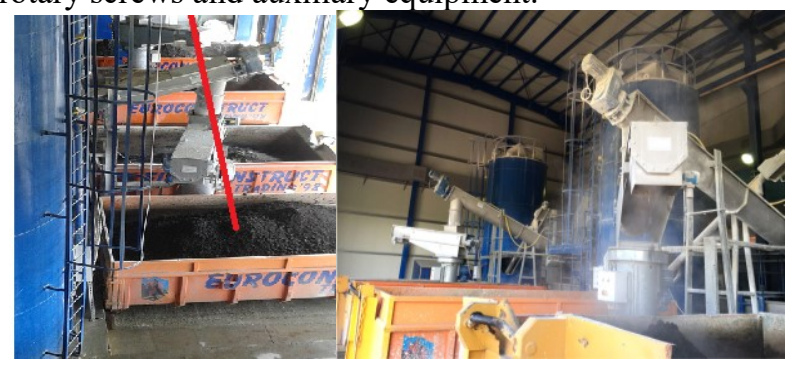

Fig. 1. Overview of the containers, lime silos, discharge system.

There are two main strategies for industrial ventilation systems: dilution ventilation and source capture/local exhaust. The working principles of the two ventilation strategies are simple. Dilution ventilation reduces the concentration of airborne contaminants by mixing the contaminated air with clean or outside air, while source capture systems usually try to remove the pollutant right at the emission source, using hoods or enclosures to reduce the probability of dispersion of the pollutant inside the room.

During the first phase of the project, presented in (Croitoru, et al., 2017), the initial dilution-based ventilation system was analyzed, and an optimization of this system has been proposed and implemented within the facility. First of all, through a series of in-situ measurements and CFD simulations, it was shown that the initial ventilation strategy was not effective in removing the ammonia and heat during summer season. The initial ventilation system for the hall (Fig. 2) was composed of 16 air inlets, placed on the rear wall at $7.5 \mathrm{~m}$ above the floor, and 16 air outlets, installed in an $8+8$ configuration on the sidewalls at $6.2 \mathrm{~m}$ above the floor.

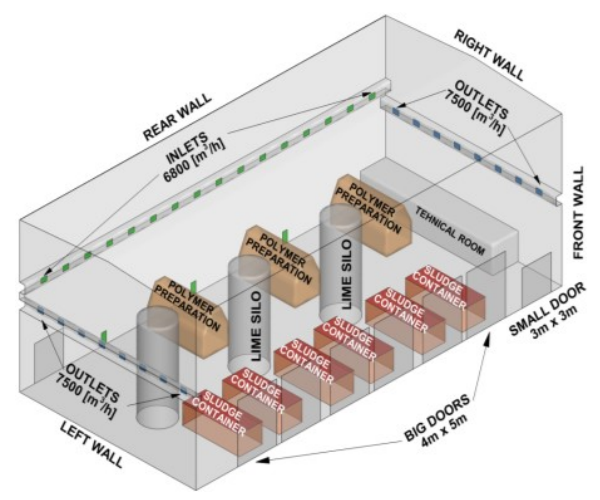

Fig. 2. Industrial hall layout and the initial ventilation system.
The on-site measurements have been performed for some key areas of the hall. As seen in Fig. 3, the main points of interest were above the sludge containers (points 1,2,3), on top of the centrifuge decanter (point 4) and at the technical room entrance (point 5). The gathered data showed that the ventilation strategy was not very efficient at removing or diluting the indoor pollutants, therefore preliminary measurements of ammonia levels have shown values of up to $60 \mathrm{mg} / \mathrm{m}^{3}$ (Table 1), which surpass the limits specified by the 2000/39/EC Directive of $14 \mathrm{mg} / \mathrm{m}^{3}$ for an $8 \mathrm{~h}$ exposure time and $36 \mathrm{mg} / \mathrm{m}^{3}$ for a $15 \mathrm{mins}$ exposure time (Table 2). The measurements have been backed up by a series of CFD simulations, where it was shown that high pollutant concentrations $\left(36 \div 60 \mathrm{mg} / \mathrm{m}^{3}\right)$ and temperatures of up to $40{ }^{\circ} \mathrm{C}$ were predicted by the numerical results. These findings were also supported by worker's complaints which were uncomfortable to execute their tasks even while wearing suits and masks. More details on the geometry and on the measurement procedure are presented in (Croitoru, et al., 2017).

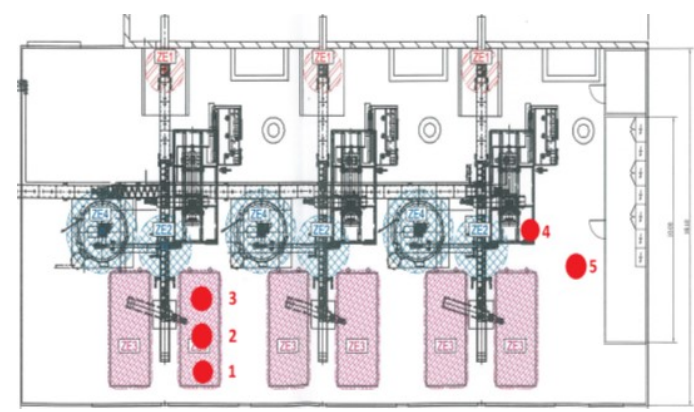

Fig. 3. Layout of the hall with the measurement points location.

Table 1. In-situ measurements for the initial ventilation system.

\begin{tabular}{|c|c|c|}
\hline Position & $\begin{array}{c}\mathrm{NH} 3 \\
\text { Concentration }\end{array}$ & $\begin{array}{c}\mathrm{CaO} \text { Particles } \\
\text { Gravimetric Method }\end{array}$ \\
\hline$[-]$ & $\mathrm{mg} / \mathrm{m}^{3}$ & $\mathrm{mg} / \mathrm{m}^{3}$ \\
\hline 1 & 33.8 & 0.74 \\
\hline 2 & 44.6 & 1.11 \\
\hline 3 & 52.6 & 1.48 \\
\hline 4 & 64.6 & 3.7 \\
\hline 5 & 47.6 & 1.85 \\
\hline
\end{tabular}

Table 2. EC 2000/39 European Directive Safety Limits.

\begin{tabular}{|c|c|c|c|}
\hline \multirow{2}{*}{$\begin{array}{c}\text { 2000/39/EC } \\
\text { Directive }\end{array}$} & Exposure time & $\mathrm{NH} 3(\mathrm{mg} / \mathrm{m} 3)$ & $\mathrm{CaO}(\mathrm{mg} / \mathrm{m} 3)$ \\
\cline { 2 - 4 } Limits: & 15 mins & 36 & 5 \\
\cline { 2 - 4 } & 8 hours & 14 & 2 \\
\hline
\end{tabular}

To provide a more adequate workplace environment, a step-by-step methodology has been proposed in order to find a cost-effective optimized solution for the general ventilation system. As a first measure, a recalculation of the airflow rates was required and an increase from the initial $\mathbf{1}$ [ach] to $\mathbf{6}$ [ach] was proposed, by raising the inlet airflow from $6800 \mathrm{~m}^{3} / \mathrm{h}$ to $50000 \mathrm{~m}^{3} / \mathrm{h}$ and the outlet airflow from $15000 \mathrm{~m}^{3} / \mathrm{h}$ to $60000 \mathrm{~m}^{3} / \mathrm{h}$. Then, the CFD simulations have shown that the initial positioning of the inlets and outlets did not 
favor the dispersion and removal of the ammonia because the inlets were placed too high and the air current was not reaching the sludge container area with a high-enough velocity to lower the pollutant concentrations in this zone. Therefore, the positioning of the inlets and outlets has been changed, as shown in Fig. 4 , in order to favor the entrainment of the pollutants. A detailed list with all the steps can be seen in (Croitoru, et al., 2017). The final optimized solution for the general ventilation system, using the same dilution strategy, has the next configuration:

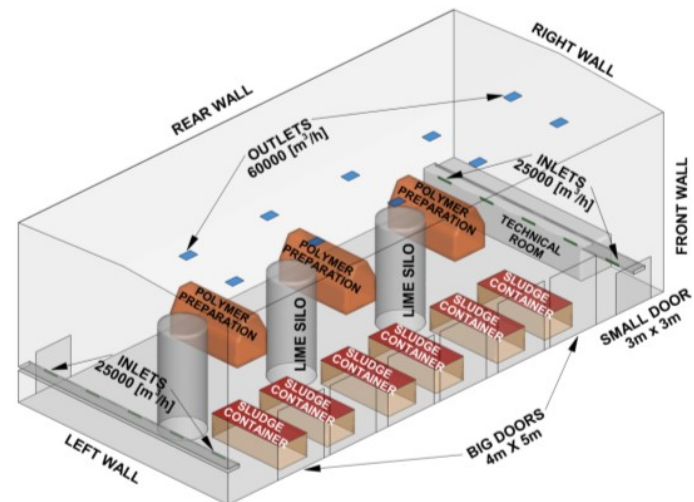

Fig. 4. Hall layout and the optimized ventilation system.

As presented in (Croitoru, et al., 2017), during the numerical analysis this new ventilation strategy has shown great improvements with regards to pollutant removal efficacy and excess heat removal. As a result, the proposed system has been applied to the industrial hall. Of course, a new measurement campaign was necessary after the implementation of the optimized ventilation system. As seen in Fig. 5, this time 3 new monitoring points were added: one between two containers (point 7), one on a second centrifuge decanter (point 8 ) and one point at the main outlet outside the building (point 9). The results from the campaign, realized in March 2018, are presented in Table 3 below. Values for point 1 and 2 have not been registered, since they were very close to the values from point 3 .

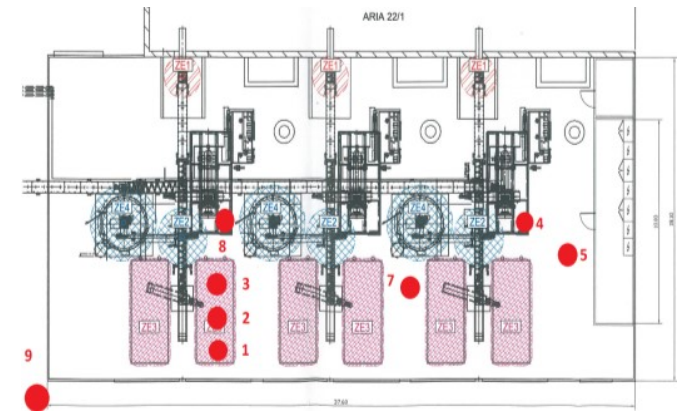

Fig. 5. Measurement points location for the optimized system.

Even though pollutant concentrations have been significantly reduced compared to the initial case, both experimental data and numerical results indicate that there are still indoor areas that surpass the safety limits mentioned by the 2000/39/EC Directive for long exposure periods. The feedback from the workers has not been positive either, as even the lower concentrations of ammonia are causing an olfactive discomfort.
Table 3. In-situ measurements for the optimized ventilation.

\begin{tabular}{|c|c|c|}
\hline Location & $\begin{array}{c}\mathrm{NH} 3 \\
\text { Concentration }\end{array}$ & $\begin{array}{c}\text { Particulate matter } \\
(\mathrm{CaO}) \\
\text { Gravimetric Method }\end{array}$ \\
\hline$[-]$ & $\mathrm{mg} / \mathrm{m}^{3}$ & $\mathrm{mg} / \mathrm{m}^{3}$ \\
\hline 3 & 12.2 & 1.2 \\
\hline 4 & 16.6 & 1 \\
\hline 5 & 8.02 & 0.9 \\
\hline 7 & 14 & 1.1 \\
\hline 8 & 9.07 & 0.9 \\
\hline 9 & 13.05 & 0.8 \\
\hline
\end{tabular}

The issues raised have shown the necessity of a local exhaust system which can capture and extract the pollutant right at the source, instead of trying to dilute the ammonia within the entire volume. Therefore, a comparison study between the optimized general ventilation system and a series of proposed local exhaust systems has been conducted and presented in this paper.

Source capture of pollutants can be a more costeffective method to ensure the air quality inside the facility because the removal of the pollutant is done right at the source, therefore the total airflow requirement should be lower. However, carefully designing the system is of utmost importance. In order to be sure that the installation functions at its best,certain aspects have to be taken into consideration during the design process, like:

1) The exhaust outlets have to placed as close as possible to the contaminant source;

2) The influence of cross drafts, moving equipment or even people should be taken into consideration, because it can lower the effectiveness of the source capture.

\section{The proposed local exhausted system}

More types of local exhaust systems have been initially proposed, but due to equipment placement and space restrictions only 2 of them seemed compatible with our design:

a) A system realized with 2 lateral ducts installed on each side of each container (Fig. 6). The introduction/exhaust surface of the ducts has been divided into 4 equal slits in order to test more ventilation strategies;

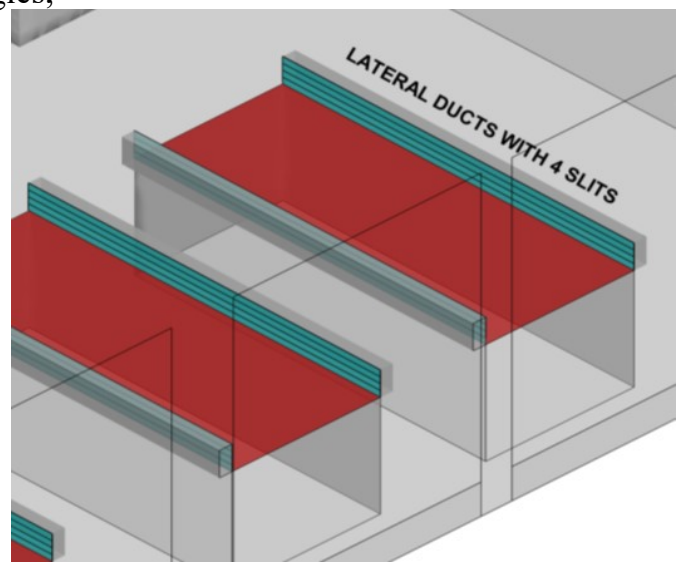

Fig. 6. Geometry of the lateral slits system. 
b) A system realized with a custom-made hood installed on top of each 2 containers. This solution is an adaptation of the usual individual exhaust hood system which was not usable in our case.

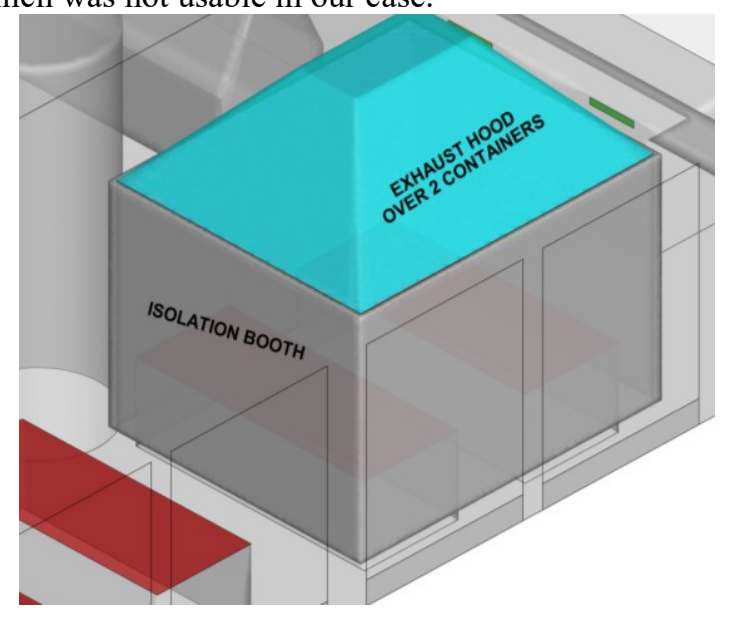

Fig. 7. Geometry of the exhaust hood system.

During this project, one of the issues encountered with the exhaust hood systems was tied to the distance from the extraction surface to the contaminant source (top of the containers) because at the end of the dewatering system there is a rotary screw that turns at $180^{\circ}$ in order to fill 2 containers from only 1 dewatering line (Fig. 1, 3 and 8). This imposed a minimum installation height of $5.2 \mathrm{~m}$ for the exhaust hoods in order to leave enough room for the rotary screw to be handled. The increased distance between the container and the hood affects the pollutant extraction efficacy and it forced us to envisage a pollutant control strategy using a custom isolation booth to delimit the discharging area of each treatment line. This booth will have the role to improve the effectiveness of the local exhaust system and it will be designed to contain the discharge rotary screw and the 2 containers in order to avoid the dispersion of the ammonia inside the hall.

Since there are no norms to design such custom installations, a computational fluid dynamics (CFD) approach has been used in order to simulate various possible scenarios, before taking the final decision regarding the design of the system.

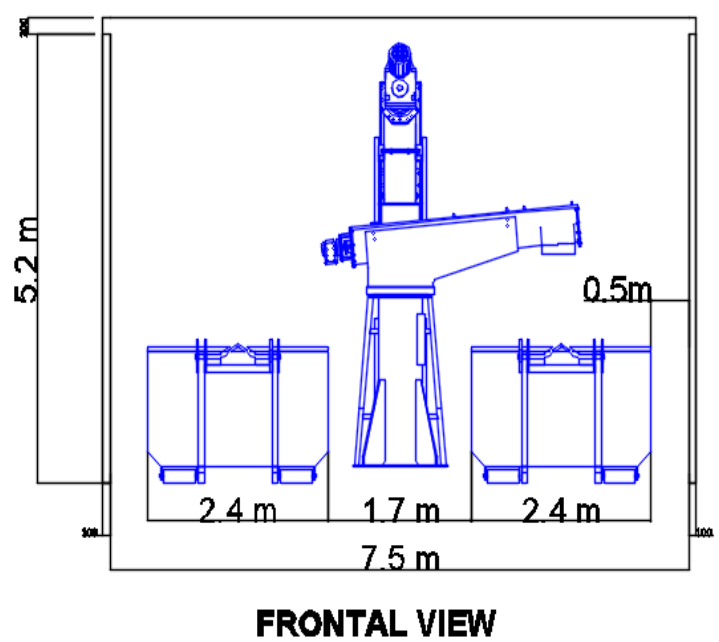

Fig. 8. Dimensions of the discharge rotary screw.

\section{The numerical model}

The numerical simulations have been carried out using the commercial CFD software ANSYS Fluent 18.2. The $3 \mathrm{D}$ virtual geometry of the model has been realized in ANSYS Space Claim and the unstructured mesh has been generated with ANSYS Meshing.

The geometry and the mesh have been adapted for each different case, thus resulting in variable mesh resolutions. The general ventilation case has been realized with 4.3 million tetrahedral elements, while the lateral slits case has a resolution of 5.5 million elements and the exhaust hood case has 7 million elements.

The configuration for the numerical model has been kept the same as specified in (Croitoru, et al., 2017). Hence the steady state simulations have been run with the $\boldsymbol{k}$ - $\boldsymbol{\omega}$ SST RANS model, with Low-Re corrections, curvature correction and production limiter.

The mixing and transport of the species has been solved using the non-reacting species transport model with diffusion energy source to account for the enthalpy of the diffused species. The mixture has been defined as a combination of air, water vapor $\left(\mathrm{H}_{2} \mathrm{O}\right)$ and ammonia vapor $\left(\mathrm{NH}_{3}\right)$. As indicated in (ANSYS Inc., 2018) the air has been considered as the bulk species and water and ammonia as dispersed species.

For the most part, the cell zone and boundary conditions have been kept the same as in (Croitoru, et al., 2017) with just a few changes:

1) The main inlets have been defined as mass flow inlets, in order to have more control over the volumetric flow of air. The temperature of the air was set to $28^{\circ} \mathrm{C}$.

2) The general outlets have been defined as pressure outlets with target mass flow rate enabled. The value of the mass flow rate depends on the scenario;

3) The local introduction/exhaust surfaces have been defined as velocity inlets, with negative values for exhaust and positive for introduction;

4) The top of the containers has been defined as mass flow inlet, resulting in a $360 \mathrm{~g} / \mathrm{h}$ total $\mathrm{NH}_{3}$ emission and $74 \mathrm{~kg} / \mathrm{h}$ total $\mathrm{H}_{2} \mathrm{O}$ emission (for all containers). The temperature of the released mixture was set to $36.5^{\circ} \mathrm{C}$.

5) At the bottom of each big door an opening has been created and defined as pressure outlet with $0 \mathrm{~Pa}$. This opening was required to maintain the balance for the mass conservation equation when using unequal inlet-outlet mass flows;

6) The main heat sources (containers, polymer production units, exterior walls, floor, rooftop, doors) have been defined with a specific heat flux that was determined for the worst-case scenario. All other components were considered at thermal equilibrium with the surrounding air.

For the solution configuration, the coupled algorithm was chosen for the pressure-velocity coupling and the spatial discretisation for all terms has been initialized with first order schemes and then changed to second order upwind to refine the solution. During the simulations, key physical quantities like $\mathrm{NH}_{3} / \mathrm{H}_{2} \mathrm{O}$ mass fractions, air velocity, air temperature and total mass imbalance were monitored in order to see when the solution reaches stability. Due to the complexity of the 
simulation, some of the residuals had difficulties in reaching the $10^{-3}$ convergence criteria, therefore monitoring the aforementioned physical values was the only solution to know when to stop the iterations. Most of the time, the model was reaching a quasi-stable state after 4000-5000 iterations.

\section{$5 \quad$ Results and discussions}

Starting with the lateral slits solution (Fig. 6), we decided to test 2 different strategies:

a) All 8 slits (4 on the left and 4 on the right of each container) have been considered as exhaust outlets, with a velocity ranging from $0.2 \mathrm{~m} / \mathrm{s}$ up to $0.4 \mathrm{~m} / \mathrm{s}$, corresponding to a total exhaust mass flow rate between $3333 \mathrm{~m}^{3} / \mathrm{h}$ and $6666 \mathrm{~m}^{3} / \mathrm{h}$ for each container.

b) The first 2 slits on the left were considered as inlets, with a velocity of $1 \mathrm{~m} / \mathrm{s}$, corresponding to a total introduced mass flow of $4167 \mathrm{~m}^{3} / \mathrm{h}$, and the other 2 slits were considered as solid walls. On the right side of the container, all 4 slits were set as exhaust surfaces, with a velocity of $0.5 \mathrm{~m} / \mathrm{s}$, corresponding to a total mass flow rate equal to the one introduced on the left side (4617 $\left.\mathrm{m}^{3} / \mathrm{h}\right)$.

For each case, the total introduced airflow has been maintained at $50000 \mathrm{~m}^{3} / \mathrm{h}$, and the total exhaust airflow was kept at $\mathbf{6 0 0 0 0} \mathrm{m}^{3} / \mathbf{h}$. However, due to the necessity of assuring the continuity of the mass conservation equation, an extra $10000 \mathrm{~m}^{3} / \mathbf{h}$ were supplied through the openings at the bottom of the big doors, which were introduced to also account for the overall infiltration.

In order to reduce the complexity of the simulations and to be able to better observe the influence of the local exhaust systems, it was decided to add the local exhaust equipment only for 3 containers, leaving the other 3 as they initially were.

For a first comparison, the $\mathbf{N H}_{3}$ concentration in $\mathrm{mg} / \mathrm{m}^{3}$ has been analysed for different section planes. In Fig. 9 we can see the $\mathrm{NH}_{3}$ contours on the $\mathrm{XZ}$ plane at $2 \mathrm{~m}$ from the front wall. As it can be observed in Fig. 9a, the OGVS does not manage to lower the overall $\mathrm{NH}_{3}$ concentration below the $14 \mathrm{mg} / \mathrm{m}^{3}$ threshold imposed by the norms for long exposure periods (European Comission, 2000). There are still areas, near and above the containers, where higher concentrations are present $\left(20-26 \mathrm{mg} / \mathrm{m}^{3}\right)$. This is where the weakness of a dilution strategy can be seen, because the mixing of the clean/outside air with the contaminated inside air is not perfect and not uniform across the volume.

In Fig. 9b, we have the results from the lateral slits with exhaust only strategy (LS-E) when a velocity of $0.3 \mathrm{~m} / \mathrm{s}$ was used. This result has presented the perfect balance between local exhaust and general exhaust airflows, having a $5000 \mathrm{~m}^{3} / \mathrm{h}$ extraction mass flow for each container, a $45000 \mathrm{~m}^{3} / \mathrm{h}$ mass flow for the general outlets and a $50000 \mathrm{~m}^{3} / \mathrm{h}$ mass flow for the general inlets (an extra $10000 \mathrm{~m}^{3} / \mathrm{h}$ were supplied through the door openings).

As it can be observed, the concentration of NH3 on the right side of the hall has been greatly reduced, presenting a very uniform distribution of the concentration which is around $6-8 \mathrm{mg} / \mathrm{m}^{3}$. This shows that the local capture solution manages to significantly reduce the dispersion of the $\mathrm{NH}_{3}$, to the point where the general ventilation system might not even need to function with such high airflow rates because the required airflow would only need to assure the thermal comfort and the fresh air necessity.

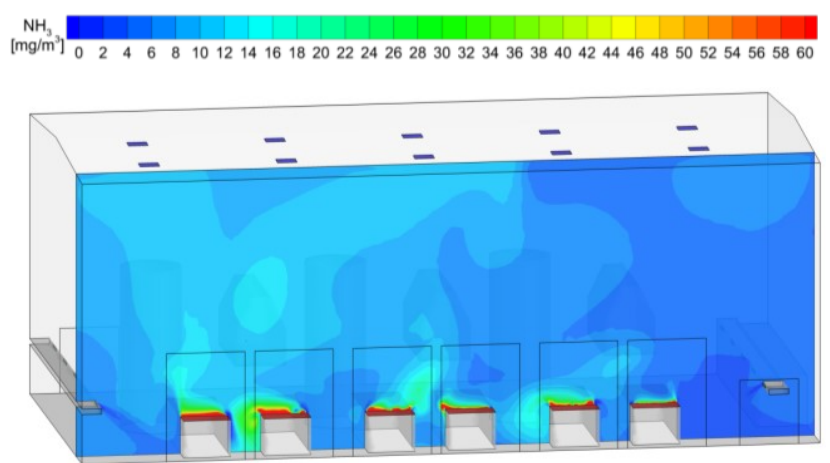

a) Optimized general ventilation system (OGVS)

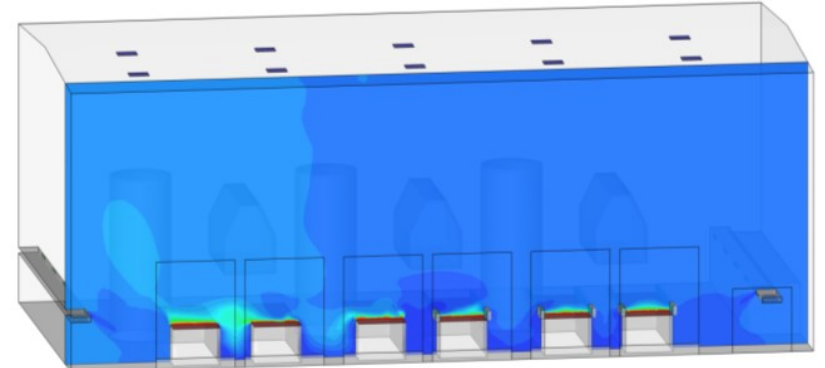

b) Lateral slits - exhaust only strategy at $0.3 \mathrm{~m} / \mathrm{s}$ (LS-E)

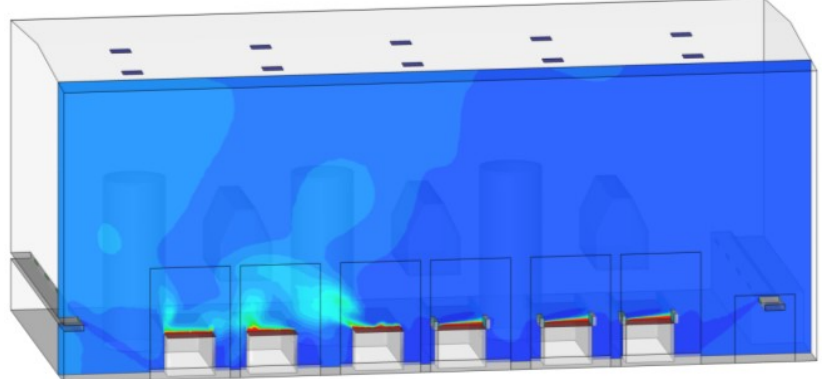

c) Lateral slits - introduction + exhaust strategy (LS-IE)

Fig. 9. $\mathrm{NH}_{3}$ contours on $\mathrm{XZ}$ plane at $2 \mathrm{~m}$ from front wall.

Further improvement can be seen in Fig. 9c, where the lateral slits with introduction-exhaust strategy (LS-IE) was used. In this case, the 2 introduction slits on the left have proven to be a great method for controlling the dispersion of the pollutant, thanks to the high impulse air that washes the surfaces of the containers and sends the mixture of $\mathrm{NH}_{3}$ and $\mathrm{H}_{2} \mathrm{O}$ vapor towards the right exhaust slits where they are removed. It can be observed that, on the right side, the concentration of $\mathrm{NH}_{3}$ was reduced from $6-8 \mathrm{mg} / \mathrm{m}^{3}$ to $2-4 \mathrm{mg} / \mathrm{m}^{3}$. Considering that this method offers a concentration that is 2 times lower than the previous one and that the required airflow per container is also reduced $\left(4167 \mathrm{~m}^{3} / \mathrm{h}\right.$ for LS-IE vs $5000 \mathrm{~m}^{3} / \mathrm{h}$ for LS-E) this shows a superiority of the LS-IE strategy, which is more effective in removing the pollutants. In the end, this means that lower airflow rates could be used in order to maintain a 
proper air quality in the hall, thus meaning that less energy will be used for the ventilation system.

The previous remarks are supported by the contours presented in Fig. 10, which represent the $\mathrm{NH}_{3}$ concentration on a plane parallel to the floor area, at a height of $1.8 \mathrm{~m}$. This height has been chosen because it is just above the container's top surface and because this is a height where the head of taller workers could be exposed to high local concentrations. We considered the worst-case scenario, knowing that the $\mathrm{NH}_{3}$ vapour normally moves towards the roof and not towards the floor area.

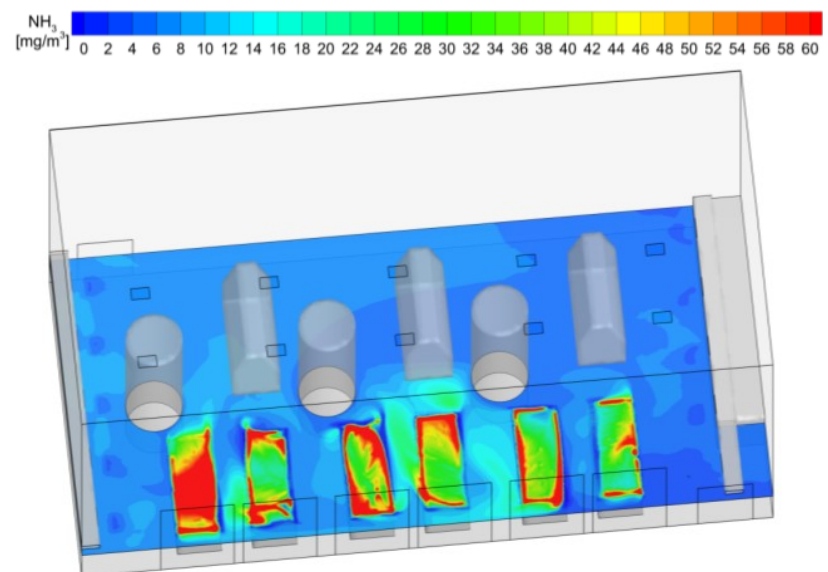

a) Optimized general ventilation system (OGVS)

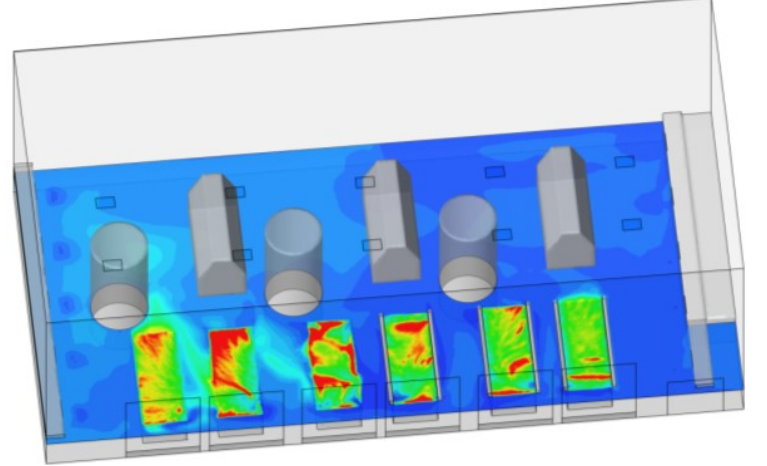

b) Lateral slits - exhaust only strategy at $0.3 \mathrm{~m} / \mathrm{s}$ (LS-E)

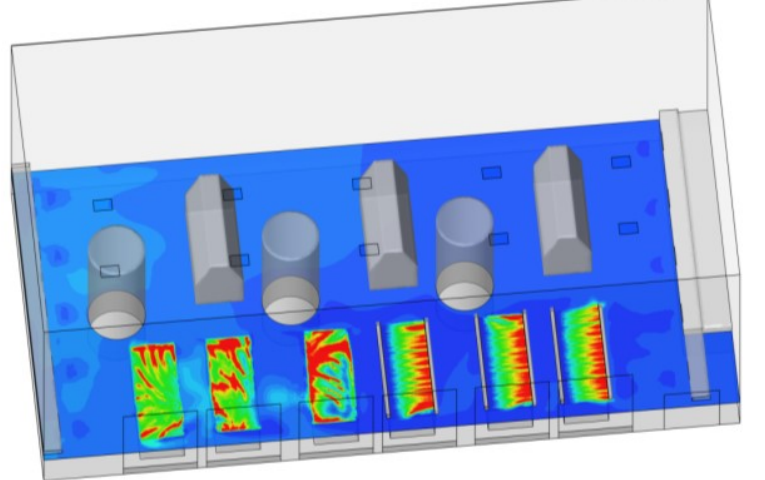

c) Lateral slits - introduction + exhaust strategy (LS-IE)

Fig. 10. $\mathrm{NH}_{3}$ contours on $\mathrm{XY}$ plane at $1.8 \mathrm{~m}$ from floor level.

In the end, despite the good results, this ventilation strategy could be hard to implement in the studied industrial hall due to several reasons. Firstly, because the system works only if the area on top of the containers remains unobstructed. However, most of the time the containers are overfilled, forming sludge piles that surpass the height of the container (Fig. 11). When this happens, the airflow trajectory is heavily affected and system efficacy is lowered. Moreover, a new duct system would be difficult to install in the lower part of the building due to the placement of the equipment. Also, the containers are frequently moved to be discharged, therefore the risk of damaging the lateral ducts is very high, since the precision of the machinery is not perfect.

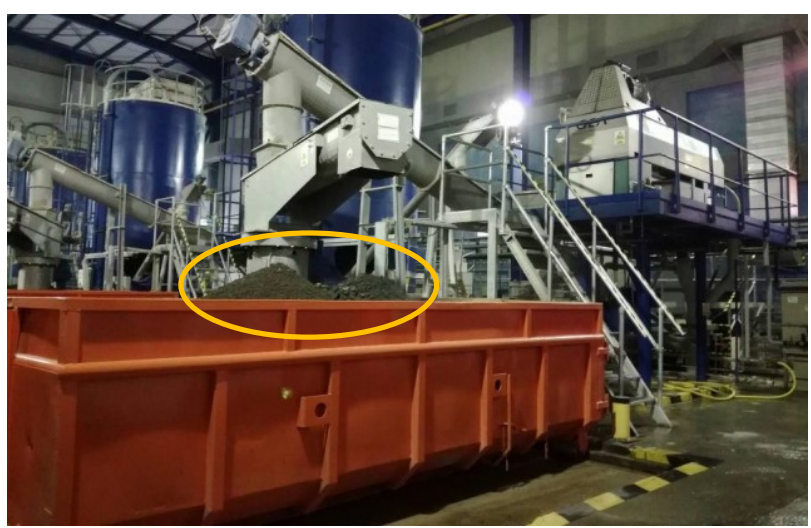

Fig. 11. Sludge piles exceeding the container height.

Consequently, a second local ventilation solution has been proposed (Fig. 7), using an adaptation of the popular local exhaust hood, to which we added an isolation booth in order to contain the pollutant and to increase the effectiveness of the extraction system. As previously mentioned, due to certain limitations the hood can only be installed at a height of $5.2 \mathrm{~m}$ above the floor. Additionally, the exhaust area of the hood is very large, so the velocity developed at the extraction surface was not high enough to prevent the dispersion of the pollutant inside the room, therefore a pollutant control solution, based only on the extraction velocity, was not possible. Hence the need for the isolation booth.

In this case, the same total airflow of $50000 \mathrm{~m}^{3} / \mathrm{h}$ for introduction, $60000 \mathrm{~m}^{3} / \mathrm{h}$ for extraction and $10000 \mathrm{~m}^{3} / \mathrm{h}$ for infiltration has been kept. From the $60000 \mathrm{~m}^{3} / \mathrm{h}$ extraction airflow rate, $20000 \mathrm{~m}^{3} / \mathrm{h}$ are extracted through the hood and $40000 \mathrm{~m}^{3} / \mathrm{h}$ are extracted through the general outlets. However, since the hood and the booth can only be installed on 2 containers at a time, it was decided to only add one booth to the CFD model in order to reduce the number of elements and the complexity of the flow. Of course, this means that a direct comparison with the lateral slits system is not very conclusive since, in this case, there are 4 containers that have no local exhaust system, instead of 3 . Therefore, we are going to compare the solution only with the dilution ventilation strategy.

Comparing Fig. 14a with Fig. 14b, the results for the exhaust hood \& booth (EHB) look promising at a first glance. We can see that the overall concentration of $\mathrm{NH}_{3}$ in the room is more uniform and that on the left side it dropped from an unacceptable value of $14-18 \mathrm{mg} / \mathrm{m}^{3}$ to under $14 \mathrm{mg} / \mathrm{m}^{3}$. This signifies that the booth does a good job in containing the pollutant from the first 2 containers. We can also notice this by looking at the high 
concentrations of $\mathrm{NH}_{3}$ inside the isolation booth and at the $\mathrm{NH}_{3}$ pathlines from Fig. 12. We can see that no particles escape the booth volume even after rendering a path of $100 \mathrm{~m}$. However, this result also shows that the exhaust hood does not manage to properly capture and extract the $\mathrm{NH}_{3}$ and $\mathrm{H}_{2} \mathrm{O}$ mixture. A closer look at the pathlines from Fig. 12 and at the velocity vectors from Fig. 13 shows that a recirculation area is formed between the containers and the extraction hood. Due to this recirculation, the $\mathbf{N H}_{3}$ accumulates inside the booth (Fig. 14b). This signifies that an increase in the extraction velocity could be necessary in order to maintain good working conditions inside the isolation booth. However, the extraction air flow rate is already very high (twice the air flow required by the LS-E solution), so a different extraction strategy might have to be employed.

Nonetheless, the EHB solution seems like the best compromise between efficacy and ease of implementation. Even though the concentrations on the XY plane (Fig. 14b) are high in certain areas, the concentrations at worker's head level (Fig. 15) are well within the recommended interval for long exposure time. The $\mathrm{NH}_{3}$ contours from Fig. 15 show values between 8$12 \mathrm{mg} / \mathrm{m}^{3}$ inside the booth. However, the accumulation in time might pose some problems because higher values of $14-20 \mathrm{mg} / \mathrm{m}^{3}$ are present between $2 \mathrm{~m}$ and $5 \mathrm{~m}$ above the floor (Fig. 14b).

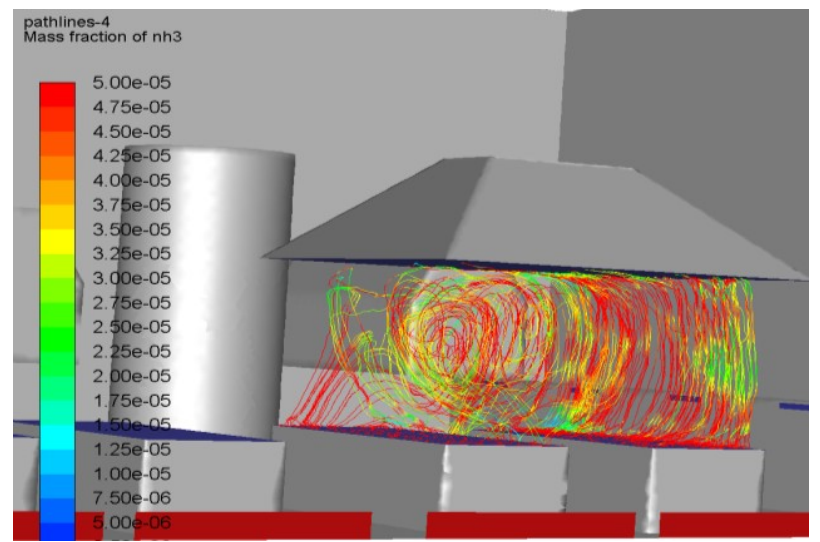

Fig. 12. $\mathrm{NH}_{3}$ pathlines escaping from the containers $(100 \mathrm{~m})$.

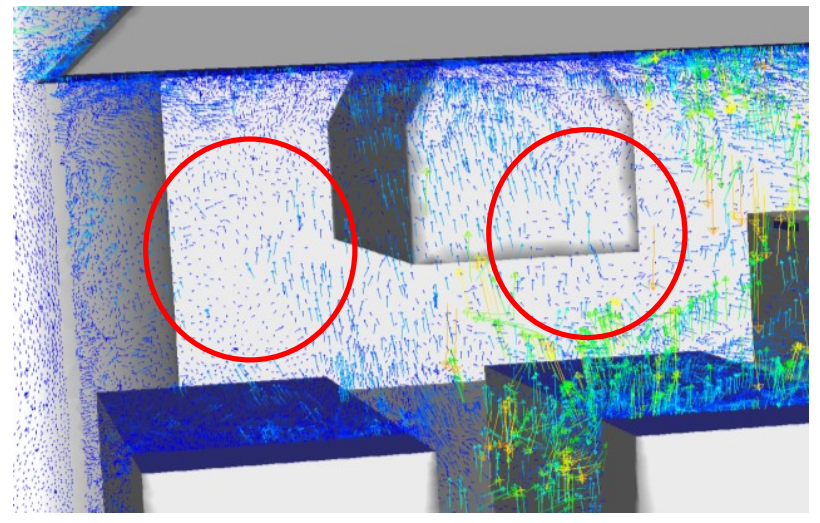

Fig. 13. Velocity vectors on $X Z$ plane at $2 \mathrm{~m}$ from front wall (recirculation areas highlighted by circles).

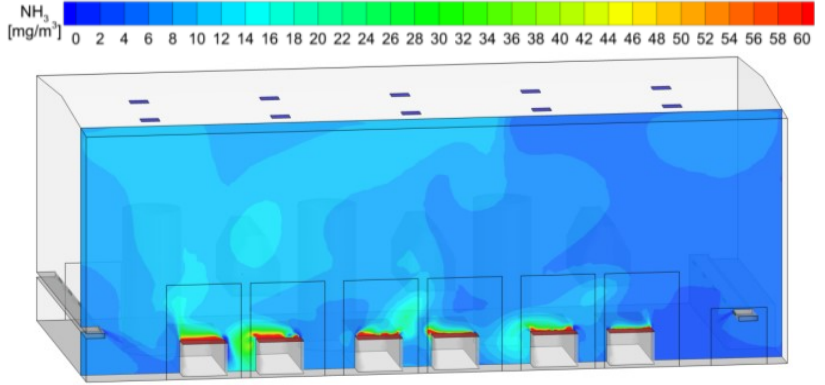

a) Optimized general ventilation system (OGVS)

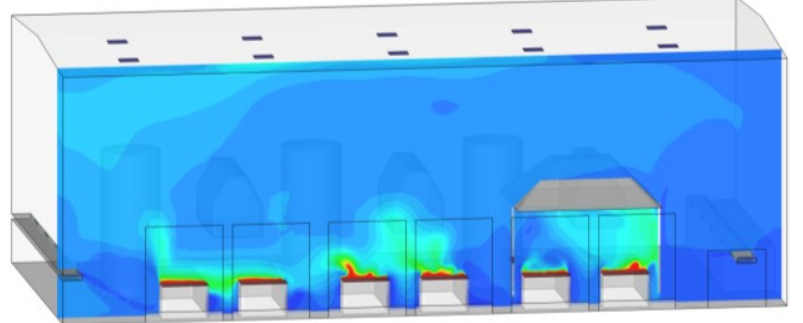

b) Exhaust Hood \& Booth strategy (EHB)

Fig. 14. $\mathrm{NH}_{3}$ contours on $\mathrm{XZ}$ plane at $2 \mathrm{~m}$ from front wall.

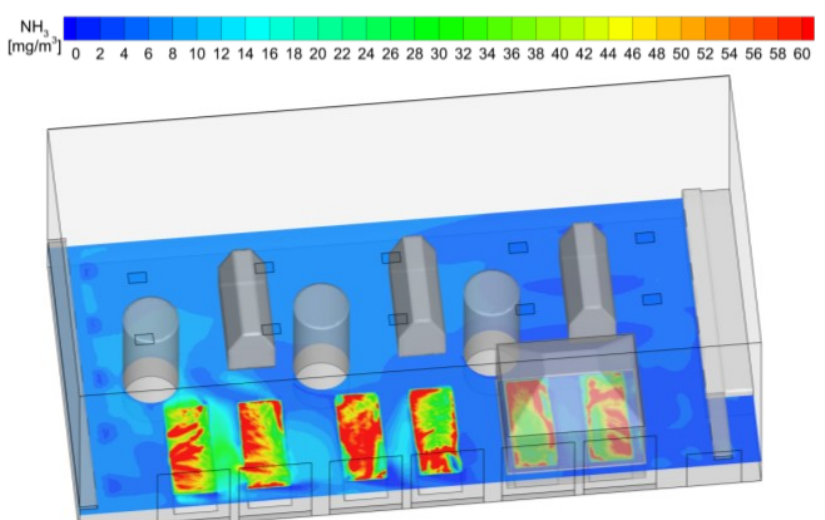

Fig. 15. $\mathrm{NH}_{3}$ contours on $\mathrm{XY}$ plane at $1.8 \mathrm{~m}$ from floor level

In the end, the booth manages to fully contain the pollutant within its internal volume. One thing that should be kept in mind is that the CFD model simulates an ideal environment where no cross drafts or air movement from the people or equipment is present and where the isolation booth is perfectly sealed. When in reality, the disturbances of the indoor air could mean a decreased efficacy for the local exhaust system, especially in the case of lateral slits where the pollutant control strategy is based only on the forced convection created by the inlet/outlet velocity. In the case of the isolation booth the chances of affecting the performance of the local exhaust system are lower because the $\mathrm{NH}_{3}$ moves towards the hood through the effect of natural convection rather than forced convection, like it's the case for lateral slits. However, in reality, infiltration/exfiltration might occur for the isolation booth and this could affect the efficacy of this system.

At the moment, other strategies for the ЕНB system are being tested, looking to reduce the extraction surface in order to increase the outlet velocity while maintaining an acceptable airflow rate. The results of the CFD simulations will be used for the final design of the local exhaust system which will be proposed to the beneficiary of the industrial hall. 


\section{Conclusions}

Industrial hygiene is a very important aspect for the working environment. Assuring healthy and safe work conditions is essential for the development of any society. Indoor air quality and thermal comfort is a crucial factor in providing an adequate work place environment, especially for the industrial sector.

The workers from the wastewater treatment facility located in Glina, Romania, have been complaining about the ammonia levels inside the facility. On-site measurements have shown that initial concentrations were outside standard safety limits. Therefore, an optimisation of the general ventilation system has been realized. However, the employees were still bothered by the sharp odour of ammonia due to high local concentrations. Results have shown that, even though the optimized general ventilation has shown a good overall IAQ improvement, it was not able to keep the ammonia levels within safe limits in the entire room. The inability of the system to locally capture and control the dispersion of the contaminants generated an unsatisfactory quality level of the indoor air which could affect the workers after long exposure periods. It was concluded that a dilution ventilation strategy alone might not be effective in this case.

In order to provide better working conditions, more local exhaust systems have been proposed for the wastewater treatment facility. The systems were firstly analysed with the help of CFD numerical simulations in order to decide the best ventilation strategies and to decide the preliminary design parameters of the installation.

The results have shown that, in this case, local exhaust solutions offer more advantages over dilution ventilation systems. Two local exhaust solutions have been proposed and analysed. The lateral slits solution with introduction-exhaust strategy has shown the best results in terms of pollutant control level. However, due to its inapplicability for this case, a second solution was studied. The custom system composed of a double exhaust hood and an isolation booth has shown promising results regarding the dispersion of ammonia. At the same time, it is the most feasible solution to implement for the wastewater treatment facility. However, due to the imposed installation height, further investigations are necessary in order to solve the $\mathrm{NH}_{3}$ accumulation problem by increasing the extraction efficacy of the hood.

In the end, this work provides a better understanding of how these two local exhaust solutions might behave in a similar scenario. This paper also represents a positive example of how useful a CFD simulation could prove to be in the HVAC design process that relies mainly on ventilation systems.

This work was supported by a Grant of the Romanian National Authority for Scientific Research, UEFISCDI, Project code: PN-III-P2-2.1-BG-2016-0158.

\section{References}

1. ACGIH. (2016). Industrial Ventilation: A Manual of Recommended Practice - 29th edition (2016). American Conference of Governmental Industrial Hygienists (ACGIH).

2. ANSYS Inc. (2018). Fluent 19 User Guide : SubChapter 14.1.4. Defining Properties for the Mixture and Its Constituent Species. ANSYS Inc.

3. Croitoru, C., Bode, F., Nastase, I., Sandu, M., Vasilescu, A., \& Tacutu, L. (2017). Sustainable Solutions for Energy and Environment, EENVIRO 2016, 26-28 October 2016, Bucharest, Romania. General ventilation system optimization study for environment improvement of sludge dewatering area from a wastewater treatment plant (pp. Energy Procedia 112 640 - 649). Bucharest: ELSEVIER - Energy Procedia.
4. European Comission. (2000, June). COMMISSION DIRECTIVE 2000/39/EC of 8 June 2000. Occupational exposure limit values in implementation of Council Directive 98/24/EC. European Comission. Retrieved from http://data.europa.eu/eli/dir/2000/39/2010-01-08

5. OSHA. (1998). Publications: OSHA 31431998 (Revised) - Informational Booklet on Industrial Hygiene. Retrieved from U.S. Department of Labor Occupational Safety and Health Administration: https://www.osha.gov/Publications/OSHA3143/OSHA3 143.htm

6. OSHA. (2011). Publications: OSHA 3430-04 Indoor Air Quality in Commercial and Institutional Buildings. Retrieved from U.S. Department of Labor Occupational Safety and Health Administration: https://www.osha.gov/Publications/3430indoor-airquality-sm.pdf

7. WHO. (2006). Development of WHO Guidelines for Indoor Air Quality - Report on a Working Group Meeting. 23-24 October, Bonn, Germany: World Health Organization Regional Office for Europe. Retrieved from $\quad$ http://www.euro.who.int/en/healthtopics/environment-and-health/air-quality/policy/whoguidelines-for-indoor-air-quality

8. Wisconsin Department of Health Services. (2000). Publications: Indoor Air Issues: Ammonia P-00810. Retrieved from Department of Health Services Wisconsin:

https://www.dhs.wisconsin.gov/publications/p0/p00810. pdf 